Whitworth Digital Commons

Whitworth University

Library Faculty Scholarship

Library

$4-2018$

\title{
Of Primary Importance: Applying the New Literacy Guidelines
}

Janet Hauck

Whitworth University, jhauck@whitworth.edu

Marc Robinson

California State University - San Bernardino

Follow this and additional works at: https:// digitalcommons.whitworth.edu/libraryfaculty

Part of the Library and Information Science Commons

\section{Recommended Citation}

Hauck, J. and Robinson, M. (2018) "Of primary importance: applying the new literacy guidelines", Reference Services Review, Vol. 46 Issue: 2, pp.217-241.

This Peer Reviewed Article is brought to you for free and open access by the Library at Whitworth University. It has been accepted for inclusion in Library Faculty Scholarship by an authorized administrator of Whitworth University. 


\title{
"Of Primary Importance: Applying the New Literacy Guidelines"
}

\begin{abstract}
Written by a librarian and a history professor, this article describes a primary source literacy project for students. In addition, this essay reports the project's effectiveness in teaching undergraduates to analyze information and develop primary source literacy. The methodology employed included a research project with 24 undergraduates, along with a pre- and post-survey. The research project and student survey incorporated principles from the Guidelines for Primary Source Literacy, published in 2017 by the ACRL's Rare Books \& Manuscripts Section and the Society of American Archivists. The article offers research and practical implications for librarians and instructors interested in strategies to teach primary source literacy. As defined by the Guidelines, "primary sources are materials in a variety of formats, created at the time under study... [They] can be printed materials, manuscript/archival materials, audio/visual materials, artifacts, or born-digital materials" (ACRL/RBMS-SAA, 2017). In keeping with this definition, this article includes a review of the literature on archival intelligence/primary source literacy, and also of artifactual literacy. This piece describes the 2017 Guidelines for Primary Source Literacy and discusses their application. Lastly, this essay includes implications on how to create an inclusive learning experience for students with mechanisms such as a scaffolded assignment, hands-on instruction, and imposter syndrome awareness. Given that this is one of the first articles to document how practitioners are incorporating the 2017 Guidelines, this is sure to be an original and valuable paper.
\end{abstract}

\section{Introduction}

Since the 2016 United States presidential election, questions of truth and accuracy have gripped the American consciousness. Terms like "fake news," "alternative facts," and "foreign disinformation" have 
highlighted the value of archival intelligence and information literacy, and the need for intentional instruction in this area. For example, Congressman Will Hurd of the House Intelligence Committee stated it was important that "we are all a little bit more critical in reviewing the information that we consume on a daily basis--and I think this is something that we should be, you know, talking about in schools when you're learning how to do a research paper..." (Lawmakers, 2017). Of course, many educators would echo Congressman Hurd's point, given that the value of analyzing sources has long been a priority for academic librarians and others, but these skills have taken on an added urgency in the current national context. This article describes a collaborative primary source literacy project involving a history professor and a librarian that aimed to better equip undergraduates to critically analyze information and execute primary source research.

The term "archival intelligence" was coined over a dozen years ago by Elizabeth Yakel and Deborah Torres in their seminal American Archivist article, "Al: Archival Intelligence and User Expertise" (Yakel and Torres, 2003). Over the intervening years, this same concept emerged with the moniker "information literacy for primary sources," and finally settled into its current iteration, "primary source literacy." The profession's ongoing discussion around these concepts has fueled the recent work of a two-year Joint Task Force commissioned by the ACRL's Rare Books \& Manuscripts Section and the Society of American Archivists. The intensive work of the Task Force culminated in the August 2017 release of the document, Guidelines for Primary Source Literacy, at the 2017 Society of American Archivists Conference in Portland, Oregon.

The release of the Guidelines has been very timely, especially for academic librarians whose institutions are placing increased focus on student learning outcomes and measures of assessment. This is certainly the case at the authors' liberal arts university, where one author, a librarian, recently partnered with the 
other author, a history professor, on an innovative primary source literacy project. Librarians have been well aware of the ACRL Information Literacy Competency Standards, approved in 2000, and their successor, the 2016 ACRL Framework for Information Literacy in Higher Education. Now a new set of standards has emerged to guide literacy instruction with primary sources, working in tandem with longstanding secondary source literacy instruction. The authors have embraced this new addition wholeheartedly.

This article will detail the collaborative project undertaken within a semester-long course on African American History, in which the authors utilized the brand-new Guidelines for Primary Source Literacy. The article will serve as a case study of the application of the Guidelines, describing student learning outcomes developed from the "Learning Objectives" section of the Guidelines, and will detail assessment measures carried out in the form of pre- and post-surveys. Also discussed will be intermediate steps taken along the way, in the form of librarian-led literacy instruction as well as professor-led content delivery. This project serves as an expanded example of the librarian's ongoing collaborative work in the digital humanities (Hauck, 2017), in which digital and digitized sources are used for research, and the resulting scholarship is presented digitally for broad access. As part of the current project, students were taught to use a number of online search tools, and the class papers receiving ' $A$ ' grades were uploaded to the institution's digital repository to serve as signposts of student learning and scholarly output. FInally, the authors will end with anticipated adjustments for potential future projects.

There are two voices present in this article; one is that of the librarian, and the other is that of the history professor. It is the authors' hope that the inclusion of both perspectives centered on a common project will add value to the analysis of the project's goals and outcomes. Ultimately, both partners undertook the project to provide greater learning opportunities for the students in the course. 


\section{Literature review}

The literature on primary source literacy has taken a linear path, with each new article building directly on the experiences and observations described in the previous one. Beginning with Yakel and Torres' article on archival intelligence (Yakel and Torres, 2003), additional articles were published every year or two focused on "information literacy for primary sources," and later on "primary source literacy." The literature chosen for this review will highlight studies that foreshadowed concepts included in the Guidelines for Primary Source Literacy, or that directly mentioned the Task Force's preliminary work. It is important to note that at least five members of the Task Force were simultaneously publishing their own studies in the literature, therefore lending informed expertise to the formulation of the Guidelines.

The concept of 'archival intelligence' was introduced by Elizabeth Yakel and Deborah Torres in their seminal 2003 American Archivist article, "Al: Archival Intelligence and User Expertise” (Yakel and Torres, 2003). Through researcher interviews, the authors sought to determine the characteristics that denoted an expert user of archives. They noted that assisting users to become experts might require "a move away from a focus on 'how to do research here' toward a more conceptual understanding of archives and search strategies" in order that users could "navigate multiple repositories and identify primary sources from afar" (Yakel and Torres, 2003). Their findings showed that "information literacy for primary sources would entail re-conceptualizing the one-shot archival orientation class into a broader and deeper curriculum" (Yakel and Torres, 2003). Yakel continued this theme in a 2004 article, where she targeted archivists and researchers in both the analog and digital realms and emphasized a move toward "defining core knowledge and skill sets that would comprise information literacy for primary sources" (Yakel, 2004). Doris Malkmus, in a 2008 article, continued this forward-looking view by stating 
that there would need to be "a good deal of joint planning and consultation between archivists and educators before primary sources could be an effective teaching tool" (Malkmus, 2008).

In their 2009 article, Archer, Hanlon, and Levine reported on a task-based study they conducted with 17 undergraduate students at the University of Maryland. They framed their results around three issues that indicated gaps in the primary source literacy of the students they studied. These three areas were direct precursors to the 2017 Guidelines: 1) definition and understanding of a primary and secondary source, 2) knowledge of special skills needed to conduct primary source research, and 3) ability to understand archival description and access. They stated, "While the importance of teaching students to use primary sources is clear, what is less evident is how to best educate students about these specialized sources" (Archer et al., 2009). The phrase "information literacy for primary sources" continued to be used in Peter Carini's 2009 article, but he stated that the scope of information literacy was too narrow. Carini noted that it did not cover areas such as the evaluation of the physical artifact (including handwriting), the importance of audience, the formation of a narrative (including perspective), date, and chronology (Carini, 2009). These additional areas are ones that have also emerged in the Guidelines.

While Yakel and Torres identified the need to go beyond a one-shot presentation, ACRL Joint Task Force member, Anne Bahde, was the first in the literature to implement this recommendation, as described in her 2013 article, "The History Labs." For this case study, Bahde and a history instructor partnered to develop a series of cumulative exercises that taught primary source literacy to students in a history survey course. They compiled a list of eight skills to be learned, which would reappear in a more succinct form in the Guidelines (Bahde, 2013). The impetus for these labs was the history instructor's concern over previous poor student performance on final papers, and Bahde was pleased to conclude that "student performance on their final papers indicates that a skills-based laboratory approach positively 
affects student achievement" (Bahde, 2013). Bahde would then go on to co-edit a book on the subject, Using Primary Sources: Hands-On Instructional Exercises. In the book, she and coeditors Heather Smedberg and Mattie Taormina promoted the importance of helping students develop archival intelligence and primary source literacy. They compiled a set of instructional exercises that represented more than the one-shot "show and tell" instruction session with primary sources, and would ultimately lead to the "the ability to analyze and interpret primary sources once they have been found" (Bahde, et al., 2014). Joint Task Force members Horowitz, Sjoberg, and Katz joined Bahde in submitting lesson ideas to the book, and all the instructional exercises were purposefully linked to learning objectives applicable to either or both partners in a librarian-professor collaborative project.

Another Joint Task Force member, Sammie Morris, followed Bahde's article with a co-authored one of her own in 2014. This article made note of the fact that no standard existed to define the primary source research competencies needed by college history students. The purpose of the study was "to identify history faculty expectations of undergraduates regarding their research skills, and, based on those expectations, to create a list of archival research competencies that could be... introduced in archival literacy sessions" (Morris et al., 2014). Through a review of history course syllabi, along with faculty interviews and comments, a list of seven categories of research competency was compiled. Again, similarities to the eventual Guidelines were apparent in this list, under headings such as "accurately conceive of primary sources," "locate primary sources," and "use a research question, evidence, and argumentation to advance a thesis." (Morris et al., 2014) In a second phase of their research, Morris and her co-authors extended their study to institutions across the United States. Their 2015 article produced a resulting list of competencies that could be "consciously and intentionally integrated into existing courses" through increased collaboration among history faculty, archivists, and librarians. (Weiner et al., 2015) They also recommended contextualizing archival literacy in history courses, assessing instruction 
and students' mastery of archival competencies, and creating practical tools and tutorials to teach archival research skills (Weiner et al., 2015)

Yet another Task Force member, Gordon Daines, co-authored a spring 2015 article that directly stated the need for "establishing primary source literacy standards that involve defining what cultural heritage professionals mean by primary source literacy, and then developing appropriate learning outcomes and learning activities" (Daines and Nimer, 2015). This article made the first mention in the literature of the creation of the Joint Task Force, and introduced the proposed literacies of evaluating, interpreting, and understanding ethical issues surrounding primary sources. Task Force member Sarah Horowitz followed in fall 2015 with her pilot assessment of student learning in special collections. Her results showed an increase in students' ability to communicate, organize, and synthesize information after working with primary materials. Horowitz noted that the "work of developing guidelines and tools for... assessing students' primary source literacy has only just begun, [and] will be an ongoing discussion in our community for many years to come" (Horowitz, 2015).

While not a Task Force member, Peter Carini, in 2016, detailed a framework for a set of standards and outcomes that would demonstrate information literacy with primary sources. He acknowledged the newly-formed Joint Task Force, and his set of six standards are in fact quite similar to the five settled upon in the Guidelines. Carini's standards included Know, Interpret, Evaluate, Use, Access, and Follow Ethical Principles. He concluded that the goal of this work is a common understanding of outcomes that will lead toward creating better users of primary sources (Carini, 2016).

The concept of primary source literacy extends beyond the use of text, into the study of artifactual and material culture. As Tabitha Tuckett and Elizabeth Lawes insightfully observed, "[For] those of us who 
are librarians and archivists working with physical special collections, 'object-based learning' appears to mean just what we have always been about, and it is more likely to be called 'working with primary sources' or 'using original materials'”(Tuckett and Lawes, 2017). Educators Paul Bolin and Doug Blandy made the case that "[students] must constantly work to develop skills that will enable [them] to 'read' carefully and insightfully the cultural expressions that permeate our world", since they are "currently engaged in multi-sensory lifestyles that extend far beyond the visual." (Bolin and Blandy, 2003). A similar statement is made in the book, Artifactual Literacies: Every Object Tells a Story, where Kate Pahl and Jennifer Rowsell declared that "literacy, as a multimodal practice, is material". They provided a list of six themes that can be applied to the study of artifacts: 1) value, 2) space, 3) timescale, 4) production, 5) mode, and 6) relation to institutions of power (Pahl and Rowsell, 2010).

The editors of Using Primary Sources: Hands-on Instructional Exercises claimed that "[object-based learning] is particularly noted for its ability to engage all learning styles, while leading students to higher order critical thinking by visually, aurally, and/or physically analyzing an object" (Bahde, Smedberg, and Taormina, 2014). In particular, the chapter by Lauren Silver provided this simple list of steps for object analysis: 1) initial observation, 2) object inquiry, 3) investigation, and 4) discussion. Jay Satterfield's chapter described learning outcomes for an artifact exercise for which students built context around an object to interrogate its cultural significance, and then developed a narrative from primary sources. (Bahde, Smedberg, and Taormina, 2014).

The National Archives and Records Administration (NARA) has long been in the business of providing guidelines for analyzing primary sources of all kinds, via their extensive set of educator resources. NARA's four-step process (National Archives and Records Administration, 2017) roughly parallels the steps set forth in the 2017 Guidelines for Primary Source Literacy, and includes: 
1. Meet the [artifact] [photograph] [video] [sound recording]

2. Observe its parts

3. Try to make sense of it

4. Use it as historical evidence

The much-anticipated 2017 release of the Guidelines for Primary Source Literacy provided a welcome addition to, as well as an intersection with, a number of other literacies, including information literacy, artifactual literacy, visual literacy, and digital literacy. "Primary source literacy" is defined in the Guidelines as "the combination of knowledge, skills, and abilities necessary to find, interpret, evaluate, and ethically use primary sources within specific disciplinary contexts, in order to create new knowledge" (ACRL/RBMS-SAA, 2017). Included in the Guidelines is a set of learning objectives that articulate broadly the knowledge, skills, and abilities needed by primary researchers. While the learning objectives do not lay out measurable outcomes, they can assist in articulating specific learning goals that can be assessed. Briefly, the five learning objectives are:

1) Conceptualize

2) Find and access

3) Read, understand, and summarize

4) Interpret, analyze, and evaluate

5) Use and incorporate

The authors of this article used these five learning objectives to inform the questions asked of students in a pre-survey and post-survey administered at the beginning and end of the primary research project. They attempted to address as many of the objectives as possible over the course of the semester through librarian-led instruction, class lecture, and one-on-one meetings between the professor and his students. What follows is an analysis of the survey results. 


\section{Survey Design and Results}

To assess how well this project helped students build primary source literacy, the authors developed a survey (see Appendix A for the complete 12-question survey) to be administered at the beginning and end of the course. The setting was a 200-level African American history course taught by one of the authors, which included 24 undergraduate students. Also, the students were mostly in their first and second year of college, and most were not history majors. Out of a total of 24 students, there were 12 freshmen, 7 sophomores, 3 juniors, and 2 seniors. Only three of the students were history majors, while the rest were majoring in a range of fields: psychology, physics, business management, and others. Overall, by the end of the semester, 17 students (71 percent) effectively used primary sources in their projects and demonstrated basic primary source literacy. The following is a partial summary of the survey findings (see Appendix B for pie charts depicting the entire set of findings).

Findings from survey Question 2A show that most students reported confidence in their ability to find primary sources by the end of the term, demonstrating what they deemed to be a firm grasp of the Guidelines' Learning Objective 2, "FInd and Access". In response to the prompt, "I have a clear understanding of how to locate primary sources," the amount of students selecting "agree" and "strongly agree" increased from 65 percent on the pre-survey (Figure 1) to 84 percent on the postsurvey (Figure 2).

Figure 1. - Question 2A Pre-Survey 


\section{Question 2A - I have a clear understanding of how to locate primary sources.}

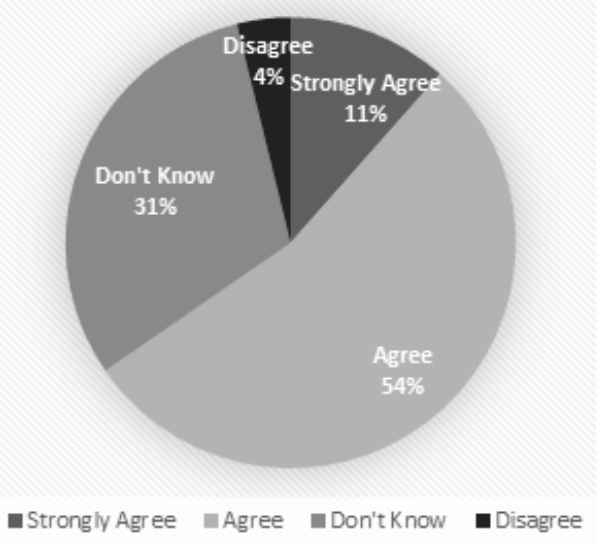

Figure 2. - Question 2A Post-Survey

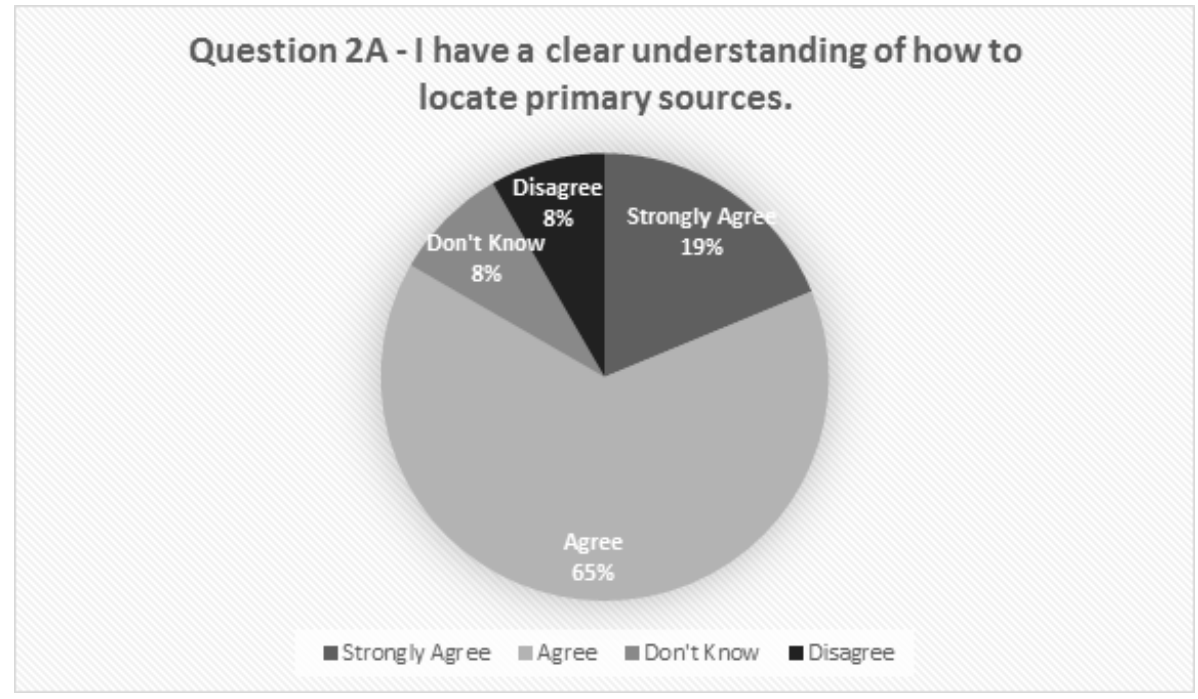

To the prompt in survey Question 1A, "I have a clear understanding of what a primary source is, in a research context," most students indicated either "agree" or "strongly agree" on the pre-survey (Figure 3) and the post-survey (Figure 4), but the "strongly agree" answers increased from 27 percent to 52 percent by the end of the term. This reiterated the conclusion that the students gained a greater familiarity with primary sources by the end of the project, and demonstrated their growth in the Guidelines' Learning Objective 1, "Conceptualize". 
Figure 3. - Question 1A Pre Survey

\section{Question $1 \mathrm{~A}-\mathrm{I}$ have a clear understaning of what a} primary source is, in a research context.

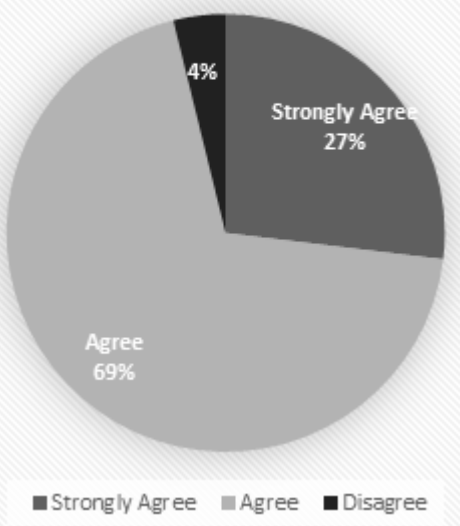

Figure 4. - Question 1A Post Survey

Question $1 \mathrm{~A}-\mathrm{I}$ have a clear understanding of what a primary source is, in a research context.

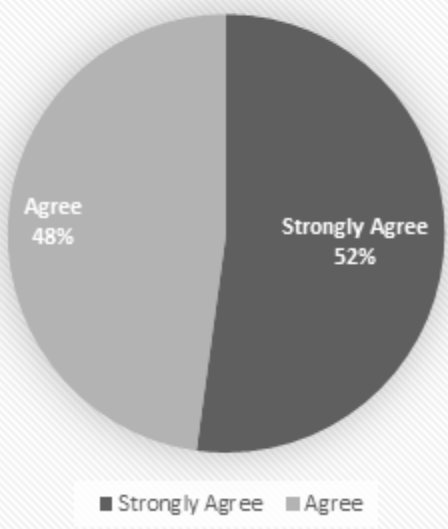

However, the surveys also indicated room for improvement. For instance, in the pre-survey (Figure 5) and post-survey (Figure 6), 25 percent of the students selected "Don't know" or "Disagree" in response to Question 1C: "I have a clear understanding of how primary and secondary sources relate to each other." In other words, the number of students indicating that they did not have an understanding of primary and secondary sources was unchanged throughout the course.

Figure 5. - Question 1C Pre-Survey 
Question $1 \mathrm{C}$-I have a clear understanding of how primary and secondary sources relate to each other.

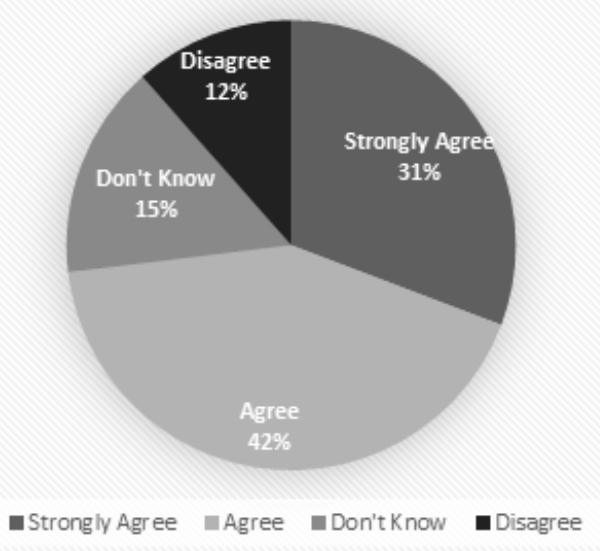

Figure 6. - Question 1C Post-Survey

\section{Question 1C-I have a clear understanding of how primary} and secondary sources relate to each other.

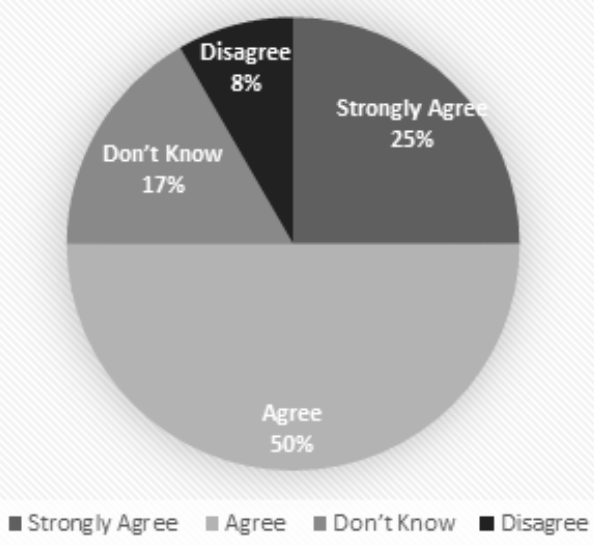

This suggests a subset of the students entered the class with limited knowledge of primary sources and did not feel they had expanded their understanding by the end of the course. Supporting this conclusion, some students were unable to accurately articulate how primary and secondary sources relate to each other in an open-ended survey question. Most students provided appropriate answers on the post-survey, for example, stating that primary and secondary sources were related because "a secondary source could be an analysis of a primary document" or "primary is from the time of said 
source." Moreover, a small number of students indicated they understood how primary and secondary sources relate, but then wrote explanations like "primary is your main source, secondary is your backup," which does not demonstrate literacy. Therefore, it seems clear that some students did not gain greater primary source literacy, which has motivated the assignment revisions described below.

\section{Background and Analysis}

Unlike a conventional historical research assignment, this project had students begin their research with a primary source. This was a brief account of an African American alumnus of the university wherein the class was taking place, often a yearbook photo and a few details gathered from alumni directories and the student newspaper. All the alumni offered for selection attended the university between 1940 and 1975, which complimented other assigned readings and course content. Students started by selecting an alumnus and then were tasked with researching the individual and larger socio-political developments during the alumnus' student experience.

To reiterate, most of the students were underclassmen and non-history majors, and 17 students (71 percent) effectively demonstrated basic primary source literacy at the end of the project. For instance, one student used a digitized 1977 article in Essence magazine in a project on the politics of black women's hair, while another searched digitized student newspaper reports to explore 1960s campus activism. A third student used the digitized college yearbook to describe the life of Frances Scott, a 1970-80s activist and educator, and a fourth utilized the sound recording of an oral history interview given by an alumnus from the 1930s. Students gained most of the context for larger socio-political developments through the use of secondary sources such as subject encyclopedias, books, and journal articles. However, many students accepted the challenge of determining context by selecting additional primary materials. For example, a student researching an African American alumnus from the 1940s 
located a number of student newspapers about the alumnus during his time as a student. Among other activities, it was learned that he had served as the regional president of the Baptist Young People's Union. Through a search of WorldCat, the student author was able to locate and borrow a copy of a 1926 publication containing a chapter on directions for BYPU presidents that reasonably might have been used by our alumnus during the time he was in office in 1942 . This primary publication epitomizes the learning outcomes apparent in Learning Objective 3, "Read, Understand, and Summarize", since the student was able to find useful information to create a scenario for inclusion in his paper the combined the knowledge he had gained about the alumnus with actions the alumnus might have taken in his leadership position.

At the close of the semester, five of the papers were deemed especially well-written and selected for inclusion in the university's institutional repository. At this time, two are currently uploaded, at https://digitalcommons.whitworth.edu/hi241/. One is an excellent example of the application of Learning Objective 5, "Use and Incorporate" in which primary and secondary sources are examined and synthesized in support of a research argument. The author of this piece has effectively used a doctoral dissertation, several books, a journal article, the university's digitized student newspapers (as primary sources), and the digitized community newspaper (as a secondary source), all in support of our institution's attention to diversity in both the past and present. The other paper uses the initial primary source provided at the beginning of the course as a springboard to explore a wider socio-political concept, illustrating Learning Objective 4, "Interpret, Analyze, and Evaluate" by situating a primary course in context through knowledge gained from a number of books and journal articles.

By analyzing the students' work, the pre- and post-survey data, and the authors' observations of the students, valuable insights have been gained about effective strategies and areas for improvement. 
These insights involve three areas: scaffolded research projects, hands-on research practice, and awareness of imposter syndrome.

\section{Scaffolded Assignments}

One insight affirmed our belief in the value of a scaffolded, or multipart, research assignment. To design the assignment, the history professor adapted materials from the Roots of Contemporary Issues program at Washington State University and created a five-part research project with due dates spread throughout the semester. As a scaffolded assignment, this project was intended to gradually build skills with progressively challenging tasks. The first step, Library Research Assignment (LRA) 1 , asked students to reflect on what they found intriguing about the initial primary source they selected, e.g. yearbook photographs of African American alumni and brief biographical facts gleaned from alumni directories. Also, they were asked to generate research questions by using Wikipedia and contemporary newspapers to find search terms and topics related to their primary source. For example, one student selected a yearbook picture because the alumnus was a black quarterback, used Wikipedia to find information on

college and professional football, and utilized newspapers to see how black quarterbacks were discussed in current society. Ultimately, this preliminary research was designed to inform a self-generated research direction.

In LRA 2, students were asked to find relevant primary and secondary sources. By this point, the students had already participated in an eighty-minute research tutorial led by the librarian, which explained primary and secondary sources and introduced electronic journal-article databases such as America: History \& Life, along with numerous other online research tools and digital archives. The databases and digital archives selected by the librarian and professor for this project were ones that, by virtue of their publishers, would contain valid and authoritative resources for students to use in their 
papers. The authors had experienced that Guideline II "Locate and Access" can be a stumbling point for students, since many do not have knowledge of how or where to find a primary source when given the directive by a professor. For this project, students conducted research in the digital archives of the New York Times Historical Newspaper Database, the Digital Public Library of America (DPLA), Britannica's ImageQuest, ArtSTOR, and the Google News Archive. Our Digital Commons institutional repository was also heavily utilized for the wealth of digitized institutional archival material curated there. These primary resources include our yearbooks (1914-2010), student newspapers (1905-2010), course catalogs (1890-2010), and alumni publications (1908-2010). In particular, the digitized yearbooks and student newspapers were extremely helpful in providing contextual information about the African American alumni assigned for the project.

As mentioned, in the LRA 2 guidelines, students were given further explanation of primary and secondary sources, were directed to find at least one monograph and one journal article, and directed to refine their research questions. In LRA 3, students had to locate one additional relevant source, create an annotated bibliography, and formulate a thesis statement. In LRA 4, they practiced bibliographic and footnote formats and drafted an outline for their final papers. By this point, they were required to have completed their research by locating a second primary source in addition to the source originally provided (most likely from the online research tools detailed above), two journal articles, and two monographs. Finally, with LRA 5 they completed and submitted the final paper.

The authors concluded that it was helpful to use the scaffolded approach like the one just described. Giving students multiple discrete steps, rather than one final due date, successfully guided them to avoid procrastinating and engage with the assignment throughout the term. It also provided opportunities for them to move from primary to secondary sources and back again, along with the need 
to consult both physical and digital resources. In addition, the approach gave periodic opportunities for the professor to assess their progress and provide feedback. Therefore, the authors have chosen to continue this strategy when another opportunity presents itself. However, an adjustment we will make is to give less time between the due dates of each step. The LRAs were typically due about three weeks apart and it seemed that some of the students had trouble retaining the research skills from step to step, LRA to LRA. For example, some students engaged primary sources in LRA 1 and 2, but abandoned those sources by LRA 3. At that point, around two-thirds of the way into the semester, the professor then had to remind the students of the assignment guidelines, and review definitions of primary and secondary sources. Thus, one adjustment for future courses is to make the research process more compact with less time between each step to help students maintain a steady level of engagement throughout the project. Another probable adjustment would be the addition of instruction for students in how to locate and evaluate digital archives on their own. This would certainly benefit them in the long run, as they continue their education and research in increasingly digital realms.

\section{Hands-on Research Practice}

Secondly, the authors found the hands-on research practice to be helpful. As mentioned earlier, an entire class period early in the semester was set aside for the students to get acquainted with primary sources and library search tools. This session, led by the librarian, featured a presentation on primary sources, physical examples of primary sources (such as university records, artifacts, photographs, and old yearbooks), and practice using online search tools and digital archives. Students were quite encouraged by the library tutorial, especially the search tools, hence hands-on experience is a practice worth continuing. 
However, it seemed that many students had difficulty retaining and remembering the research skills later in the semester, months after the library session. The authors anticipated this might happen and encouraged students to see the librarian with questions, but many never did. A few students did follow up with the librarian and received significant research assistance, but many others did not seek help until late in the semester, or not at all. This outcomes lends itself to another point for adjustment. Like Bahde's "History Labs" approach mentioned in this essay's literature review, the authors concluded that one library tutorial was simply not enough. Like any skill, using research tools and engaging with primary sources requires practice, and multiple research tutorials were needed to maximize the retention of knowledge. Moreover, the authors found that many of the students who needed the most guidance in navigating sources were the least likely to seek help. Thus, in the next iteration, a recurring research component will be implemented. The plan is to have six research labs during a semester, with three clustered near the beginning of the term and the other three near the end. Each lab will be integrated into the class, therefore designated class meetings will include course content from the professor and a research tutorial guided by the librarian.

The authors believe this approach will enable the reiteration of primary source literacy and research skills in a way that mitigates short-term memory. It also ensures that all students have ample time to get research training, even if they are hesitant to ask for help. Using guidelines for information literacy and primary source literacy, the librarian will develop a series of learning modules, one for each research lab, that the authors believe will produce better learning outcomes for the students. So, instead of 71 percent of the students effectively using primary sources, the hope is for 90 or 100 percent success rate next time.

\section{Imposter Syndrome}


The final insight from this experience pertains to what many have called the "imposter syndrome." This is the feeling that one does not feel confident within an institution. Two psychologists, Pauline Clance and Suzanne Imes, first coined this term in 1978 and they described it as a feeling of "phoniness in people who believe that they are not intelligent, capable or creative despite evidence of high achievement" (Richards, 2015). Specifically, in an educational context, a professor with imposter syndrome might feel unqualified despite successfully passing a rigorous hiring process. Likewise, a student with imposter syndrome might feel like they do not deserve to be in college. In a research context, a manifestation of imposter syndrome can be a reluctance to seek help and meet with the librarian or instructor. This seemed to be a particular hurdle for some of the students in our class. There was likely a correlation between the students who did not show primary source literacy in their final papers and students who were especially reluctant to seek assistance.

The authors did not initially account for this, but will do so in future assignment designs to better engage all students. Although most people have likely felt anxiety about their academic abilities at some point, much research suggests "women, people of color, and first-generation college student" are "particularly prone to impostor syndrome" (Herrmann, 2016). For instance, a recent study from the University of Texas at Austin and published in the Journal of Counseling Psychology reiterated the salience of imposter syndrome for students of color and "suggests that the impostor phenomenon in some cases can degrade the mental health of minority students who already perceive prejudices against them" (Bauer-Wolf, 2017). Among students who struggled with the assignment, the professor had extensive interactions with two students of color. He concluded both were experiencing some degree of imposter syndrome, and were embarrassed to ask for help. This issue of imposter syndrome is another reason the authors have instituted the recurring research lab in future plans, in order to show anxious students the acceptability of seeking assistance from faculty and librarians. 


\section{Conclusion}

In conclusion, the authors' main goal was to promote broader information literacy by teaching specific skills about primary source literacy. The 2017 Guidelines for Primary Source Literacy provided the impetus for a collaborative project that gave increased focus on the teaching of certain skills, and the assessment of those skills using an informed pre- and post-survey instrument. While it is likely that the librarian and professor would have collaborated on a project of this nature anyway, being able to utilize and assess the Guidelines gave the project added focus. The largest impact was felt through the authors' assessment of both the survey data and the resulting student papers. Seeing that some improvement occurred in primary source literacy over the course of the semester, but also knowing that much more improvement had been desired, the authors have created a revised assignment design that will involve six librarian-led instruction sessions, rather than just one session. It is hoped and expected that this increase in instruction and student practice will lead to greater facility with primary sources, along with more dramatic growth in understanding, as demonstrated by a future post-survey. As students become adept at using and interpreting primary sources, they will have acquired valuable skills that will serve them well in today's information climate.

\section{References}

ACRL RBMS-SAA Joint Task Force on the Development of Guidelines for Primary Source Literacy (2017), Guidelines for Primary Source Literacy, available at:

https://www2.archivists.org/sites/all/files/Guidelines\%20for\%20Primary\%20Souce\%20Literacy\%20\%20FinalVersion\%20-\%20Summer2017 0.pdf (accessed 18 February 2018). 
Archer, J., Hanlon, A. M. and Levine, J. A. (2009), "Investigating primary source literacy", Journal of Academic Librarianship, Vol. 35 No. 5, pp. 410-420.

Bahde, A. (2013), "The history labs: integrating primary source literacy skills into a history survey course", Journal of Archival Organization, Vol. 11 No. 3-4, pp. 175-204.

Bahde, A., Smedberg, H., and Taormina, M. (2015) Using Primary Sources: Hands-on Instructional Exercises, Libraries Unlimited, Santa Barbara, CA.

Bauer-Wolf, J. (2017), "Feeling like impostors", Inside Higher Ed, available at https://www.insidehighered.com/news/2017/04/06/study-shows-impostor-syndromes-effect-minoritystudents-mental-health (accessed 19 February 2018).

Bolin, P. and Blandy, D. (2003), "Beyond visual culture: seven statements of support for material culture studies in art education", Studies in Art Education, Vol. 44 No. 3, pp. 246-263.

Carini, P. (2009), “Archivists as educators: integrating primary sources into the curriculum”, Journal of Archival Organization, Vol. 7 No. 1-2, pp. 41-50.

Carini, P. (2016), “Information literacy for archives and special collections: defining outcomes", portal: Libraries and the Academy, Vol. 16 No. 1, pp. 191-206.

Daines, J. G., III and Nimer, C. L. (2015), “In search of primary source literacy: opportunities and challenges", RBM: A Journal of Rare Books, Manuscripts, and Cultural Heritage, Vol. 16 No. 1, pp. 19-34. 
Hauck, J. (2017), “From service to synergy: embedding librarians in a digital humanities project", College and Undergraduate Libraries, Vol. 24 No. 1, pp. 434-51.

Hensley, M. K., Murphy, B. P., and Swain, E. D. (2014), “Analyzing archival intelligence: a collaboration between library instruction and archives", Communications in Information Literacy, Vol. 8 No. 1, pp. 96114.

Herrmann, R. (2016), “Advice: Imposter Syndrome is definitely a thing”, The Chronicle of Higher Education, available at https://www.chronicle.com/article/Impostor-Syndrome-Is/238418 (accessed 19 February 2018).

Horowitz, S. M. (2015), "Hands-on learning in special collections: a pilot assessment project", Journal of Archival Organization, Vol. 12 No. 3-4, pp. 216-229.

Jarosz, E. E. and Kutay, S. (2017), “Guided resource inquiries: integrating archives into course learning and information literacy objectives", Communications in Information Literacy, Vol. 11 No. 1, pp. 204-220.

“Lawmakers meet with Twitter reps after Russia spreads misinformation." (2017), Morning Edition, National Public Radio, available at https://www.npr.org/2017/09/29/554447478/lawmakers-meet-withtwitter-reps-after-russia-spreads-misinformation (accessed 23 February 2018).

Malkmus, D.J. (2008), "Primary source research and the undergraduate: a transforming landscape”, Journal of Archival Organization, Vol. 6 No. 1-2, pp. 47-72. 
Morris, S., Mykytiuk, L. J., and Weiner, S. A. (2014), “Archival literacy for history students: identifying faculty expectations of archival research skills", American Archivist, Vol. 77 No. 2, pp. 394-424.

National Archives and Records Administration (2017), "Artifact analysis worksheet", available at https://www.archives.gov/files/education/lessons/worksheets/artifact analysis worksheet.pdf (accessed 18 April 2018).

National Archives and Records Administration (2017), "Motion picture analysis worksheet", available at https://www.archives.gov/files/education/lessons/worksheets/motion picture analysis worksheet.pdf (accessed 18 April 2018).

National Archives and Records Administration (2017), "Photo analysis worksheet", available at https://www.archives.gov/files/education/lessons/worksheets/photo analysis worksheet.pdf (accessed 18 April 2018).

National Archives and Records Administration (2017), "Sound recording analysis worksheet", available at https://www.archives.gov/files/education/lessons/worksheets/sound recording analysis worksheet.pd f (accessed 18 April 2018).

Pahl, K. and Rowsell, J. (2008), "Artifactual critical literacy: a new perspective for literacy education", Berkeley Review of Education, Vol. 2 No. 2, pp. 129-151.

Pahl, K. and Rowsell, J. (2010) Artifactual Literacies: Every Object Tells a Story, Teachers College Press, New York, NY. 
Richards, C. (2015), "Learning to deal with the imposter syndrome", The New York Times, available at https://www.nytimes.com/2015/10/26/your-money/learning-to-deal-with-the-impostor-syndrome.html (accessed 19 February 2018).

Satterfield, J. (2015), "Covered with culture: finding meaning on a stick", in Bahde, A., Smedberg, H., and Taormina, M. (eds.), Using Primary Sources: Hands-on Instructional Exercises, Libraries Unlimited, Santa Barbara, CA, pp. 125-128.

Silver, L. (2015), "Infinitely adaptable: using objects to promote inquiry-based learning", in Bahde, A., Smedberg, H., and Taormina, M. (eds.), Using Primary Sources: Hands-on Instructional Exercises, Libraries Unlimited, Santa Barbara, CA, pp. 21-26.

Tuckett, T. and Lawes, E. (2017), “Object literacy at University College London Library Services”, ALJ, Vol. 42 No. 2, pp. 99-106.

Weiner, S. A., Morris, S., and Mykytiuk, L. J. (2015), “Archival literacy competencies for undergraduate history majors", American Archivist, Vol. 78 No. 1, pp. 154-180.

Yakel, E. (2004), “Information literacy for primary sources: creating a new paradigm for archival research education", OCLC Systems \& Services, Vol. 20 No. 2, pp. 61-64.

Yakel, E. and Torres, D. (2003), “Al: archival intelligence and user experience”, American Archivist, Vol. 66 No. 1 , pp. 51-80. 